\title{
EDITORIAL
}

\section{Focus on post-resuscitation care}

\author{
Claudio Sandroni ${ }^{1^{*}}$ (D) Alain Combes ${ }^{2}$ and Jerry P. Nolan ${ }^{3}$
}

(c) 2019 Springer-Verlag GmbH Germany, part of Springer Nature

Keywords: Cardiac arrest, Cerebral perfusion pressure, Coronary angiography, Hypoxic brain damage, Magnetic resonance imaging, Mechanical ventilation, Near-infrared spectroscopy, Prognosis, Targeted temperature

management

In patients who are admitted to an intensive care unit after resuscitation from cardiac arrest (CA) mortality attains $60-70 \%$ [1]. Two-thirds of these deaths are due to hypoxic-ischaemic brain injury (HIBI) and occur mainly after $72 \mathrm{~h}$, as a result of withdrawal of life-sustaining treatment (WLST) based on the prediction of a poor neurological outcome [2]. The second most common cause of post-resuscitation death, especially in the very early phase after return of spontaneous circulation (ROSC), is circulatory failure. Current research on postresuscitation care focuses on interventions aimed at reducing these two important causes of morbidity and mortality after CA.

\section{Temperature management and coronary angiography}

Targeted temperature management (TTM) for $24 \mathrm{~h}$ after ROSC is recommended to reduce HIBI, but the optimal temperature is unclear $[2,3]$. A recent multicentre pilot randomised clinical trial (RCT) assigned comatose survivors of witnessed out-of-hospital CA (OHCA) from ventricular fibrillation/ventricular tachycardia (VF/VT) to TTM at $32{ }^{\circ} \mathrm{C}(n=52), 33{ }^{\circ} \mathrm{C}(n=49)$ or $34{ }^{\circ} \mathrm{C}(n=49)$, see Table 1 . Cooling was tolerated well, but 90-day neurological outcome did not differ among groups [4]. Patients cooled to $32{ }^{\circ} \mathrm{C}$ had lower rates of WLST due to severe

\footnotetext{
*Correspondence: claudio.sandroni@policlinicogemelli.it

${ }^{1}$ Istituto Anestesiologia e Rianimazione Università Cattolica del Sacro

Cuore, Fondazione Policlinico Universitario "Agostino Gemelli" IRCCS, Largo Francesco Vito, 1, 00168 Rome, Italy

Full author information is available at the end of the article
}

HIBI. Cooling to this temperature may be the focus of further research.

Immediate coronary angiography is recommended in survivors of OHCA with ST-segment elevation (STE) on their electrocardiogram [1], but the benefit of this intervention after non-STE OHCA is uncertain. The multicentre COACT trial, which included 552 non-STE patients resuscitated from VF/VT OHCA, showed that an immediate vs. a delayed angiography strategy (median [IQR] 2.3 [1.8-3.0] vs. 121.9 [52.0-197.3] h from arrest) was not associated with higher 90 -day survival (64.5 vs. $67.2 \%$; $p=0.51$ ) [5]. Acute unstable coronary lesions were found in less than $20 \%$ of the patients in this trial. Future studies may focus on non-STE patients more likely to benefit from immediate percutaneous coronary interventions (PCI). A recent retrospective study on 1,410 resuscitated $\mathrm{OHCAs}$ also suggested that only patients with low risk of in-hospital death according to the Cardiac Arrest Hospital Prognosis score benefited from early PCI [6].

\section{Oxygenation and ventilation, and cerebral perfusion}

Observational evidence suggests that hyperoxia may be associated with worse neurological outcome after CA, while mild hypercapnia and higher mean arterial blood pressure (MAP) may be associated with better neurological outcome [2]. The COMACARE pilot multicentre RCT evaluated the feasibility of targeting low-normal (4.5-4.7 kPa) vs. high-normal (5.8-6.0 kPa) $\mathrm{PaCO}_{2}$, normoxia $\left(\mathrm{PaO}_{2} 10-15 \mathrm{kPa}\right)$ vs. moderate hyperoxia $\left(\mathrm{PaO}_{2}\right.$ $20-25 \mathrm{kPa})$ and low-normal $(65-75 \mathrm{mmHg})$ vs. highnormal $(80-100 \mathrm{mmHg})$ MAP $[7,8]$ during the first $36 \mathrm{~h}$ after ROSC in 123 comatose patients resuscitated from

\section{Springer}




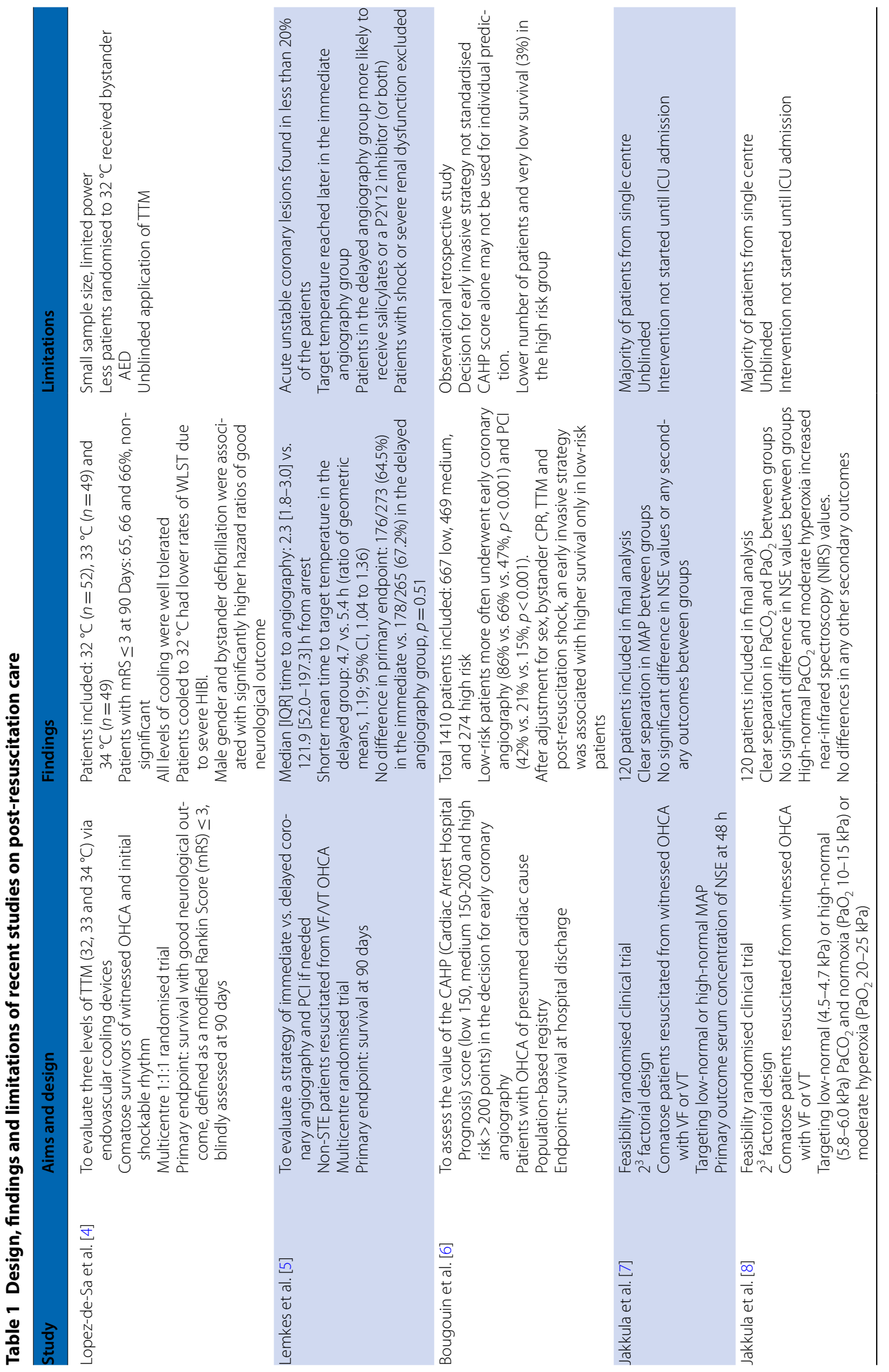




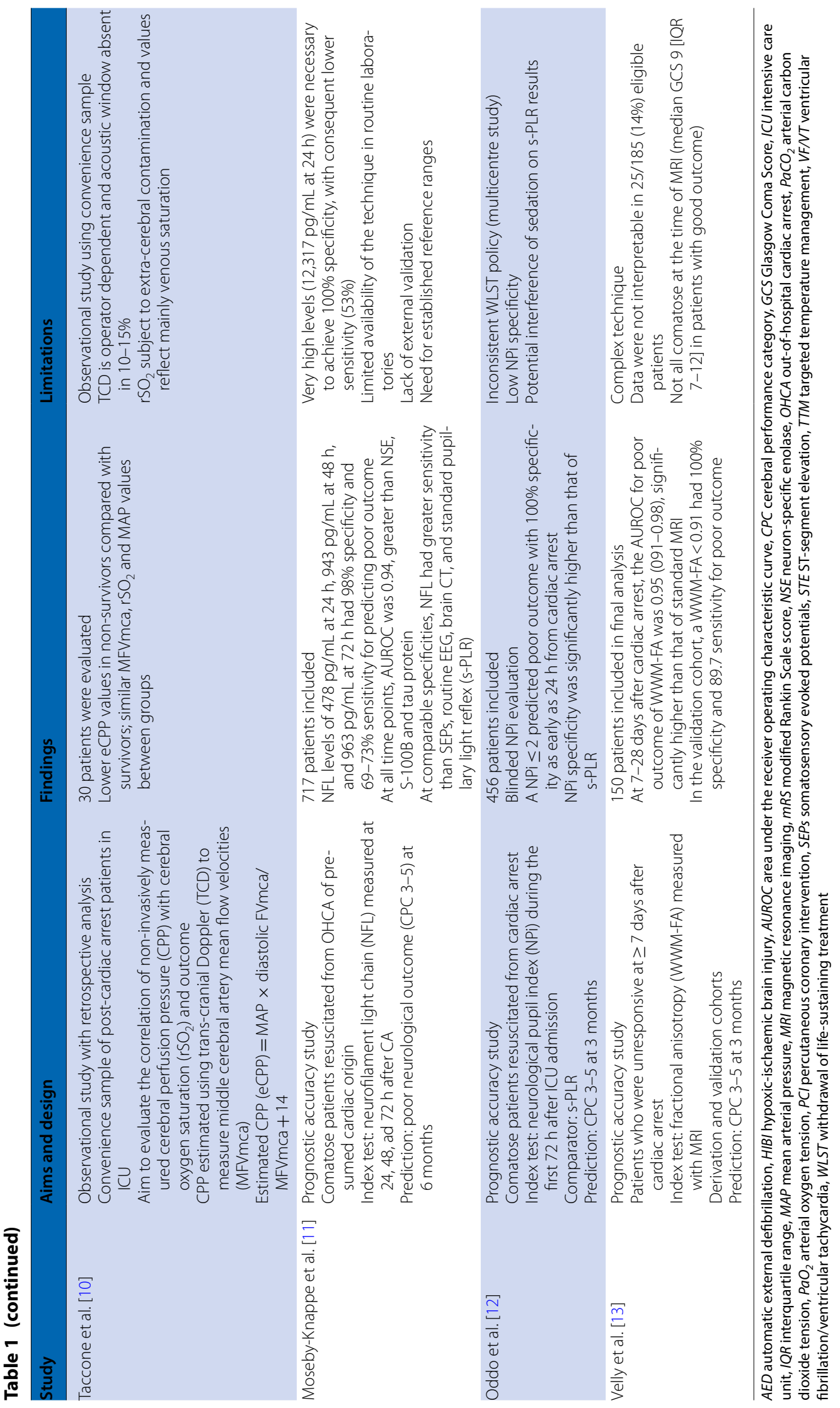


VF/VT OHCA. The investigators achieved clear separation in $\mathrm{PaO}_{2}, \mathrm{PaCO}_{2}$ and MAP between the groups but there was no difference in the values of neuron-specific enolase (NSE), a biomarker of HIBI, at $48 \mathrm{~h}$ after ROSC. High-normal $\mathrm{PaCO}_{2}$ and moderate hyperoxia increased regional cerebral oxygenation $\left(\mathrm{rSO}_{2}\right)$ but there were no differences between the groups in any of the secondary outcomes.

One of several reasons for the failure to replicate the findings of previous observational studies is the likely considerable heterogeneity in optimal targets among patients. Approximately a third of post-CA patients will lose cerebral autoregulation and are likely to require a higher MAP to preserve cerebral blood flow [9]. $\mathrm{rSO}_{2}$ has been used to determine optimal MAP in post-CA patients but it is unknown how well $\mathrm{rSO}_{2}$ correlates with cerebral perfusion pressure (CPP). Taccone and colleagues have used trans-cranial Doppler to assess middle cerebral artery mean flow velocities (MFVmca) in 30 post-CA patients to provide an estimate of CPP (eCPP) [10]. Lower eCPP values were found in non-survivors compared with survivors, while MFVmca, $\mathrm{rSO}_{2}$ and MAP values were similar between groups. It is possible that strategies to optimise eCPP instead of MAP or $\mathrm{rSO}_{2}$ may improve neurological outcome.

\section{Prognostication}

Prediction of neurological outcome in comatose-resuscitated patients is challenging. Among indices for estimating severity of HIBI, NSE has several advantages: potential for blinded evaluation-therefore avoiding a self-fulfilling prophecy bias-and no influence from sedation and TTM. However, to obtain a specificity close to $100 \%$ for the prediction of poor outcome, very high levels are needed, and the consequent sensitivity is low. Moreover, NSE values are influenced by haemolysis [1].

In a substudy of the TTM trial [11], a new biomarkerneurofilament light chain (NFL)-was assessed blindly for neuroprognostication after CA. At $24 \mathrm{~h}$, a NFL value of $478 \mathrm{pg} / \mathrm{mL}$ predicted poor neurological outcome at 6 months with 69 [57-79]\% sensitivity and 98 [96-100]\% specificity. The area under the receiver operating characteristic curve was $0.94(0.92-0.95)$, greater than that of any other predictor, including NSE, brain CT, somatosensory evoked potentials, EEG, and clinical examination. Unlike NSE, NFL blood values are not influenced by haemolysis.

Clinical examination is crucial for neuroprognostication and absence of standard pupillary light reflex (sPLR) at $\geq 72 \mathrm{~h}$ is recommended as a robust predictor of poor neurological outcome after CA [1]. However, sPLR is operator dependent, qualitative and, since it cannot be concealed from the treating team, is prone to self-fulfilling prophecy bias. In a European 456-patient multicentre prognostication study [12] where the quantitative neurological pupil index (NPi) measured blindly using automated pupillometry was compared with sPLR, an $\mathrm{NPi} \leq 2$ during the first $72 \mathrm{~h}$ after ROSC had significantly higher specificity than an absent $\operatorname{sPLR}(p<0.001)$. NPi predicted unfavourable outcome with $0 \%$ FPR as early as $24 \mathrm{~h}$ after CA. Among patients whose sPLR was scored as absent, those with false positives had a significantly smaller pupil size than those who had a poor neurological outcome $(1.9 \pm 0.22$ vs. $2.8 \pm 1.05 \mathrm{~mm}$; $p=0.009$ ), suggesting that miosis may have prevented clinicians from detecting sPLR.

Neuroprognostication guidelines focus on the early post-resuscitation phase (72-96 h), while little is known about late predictors. In a multicentre prognostication study [13], fractional anisotropy (WWM-FA) measured on magnetic resonance imaging (MRI) was evaluated as a predictor of poor neurological outcome at 6 months in post-ROSC patients who had been unconscious for at least 7 days. A WWM-FA threshold of 0.91 was identified in a 150-patient derivation cohort as a prediction and subsequently tested in a 50-patient validation cohort, where it showed 89.7 (75.8-97.1) \% sensitivity and 100 (69.1-100) \% specificity for prediction of poor outcome. Despite its complex measurement, WWM-FA is a promising predictor in late awakeners after CA.

\section{Author details \\ ${ }^{1}$ Istituto Anestesiologia e Rianimazione Università Cattolica del Sacro Cuore, Fondazione Policlinico Universitario "Agostino Gemelli"IRCCS, Largo Francesco Vito, 1, 00168 Rome, Italy. ${ }^{2}$ Sorbonne Université, INSERM, UMRS_1166-ICAN, Institute of Cardiometabolism and Nutrition, and Service de médecine intensive-réanimation, Institut de Cardiologie, APHP Hôpital Pitié-Salpêtrière, 75013 Paris, France. ${ }^{3}$ Department of Anaesthesia, Royal United Hospital, Bath, and Warwick Medical School, University of Warwick, Coventry CV4 7A, UK.}

\section{Compliance with ethical standards}

\section{Conflicts of interest}

On behalf of all authors, the corresponding author states that there is no conflict of interest.

\section{Publisher's Note}

Springer Nature remains neutral with regard to jurisdictional claims in published maps and institutional affiliations.

Received: 28 May 2019 Accepted: 5 June 2019

Published online: 25 June 2019

\section{References}

1. Nolan JP, Soar J, Cariou A, Cronberg T, Moulaert VR, Deakin CD, Bottiger BW, Friberg H, Sunde K, Sandroni C, European Resuscitation C, European Society of Intensive Care M (2015) European Resuscitation Council and European Society of Intensive Care Medicine 2015 guidelines for postresuscitation care. Intensive Care Med 41:2039-2056

2. Nolan JP, Berg RA, Callaway CW, Morrison LJ, Nadkarni V, Perkins GD, Sandroni C, Skrifvars MB, Soar J, Sunde K, Cariou A (2018) The present and 
future of cardiac arrest care: international experts reach out to caregivers and healthcare authorities. Intensive Care Med 44:823-832

3. Aneman A, Cariou A, Nolan JP (2018) Understanding temperature goals after cardiac arrest. Intensive Care Med 44:940-943

4. Lopez-de-Sa E, Juarez M, Armada E, Sanchez-Salado JC, Sanchez PL, Loma-Osorio P, Sionis A, Monedero MC, Martinez-Selles M, MartinBenitez JC, Ariza A, Uribarri A, Garcia-Acuna JM, Villa P, Perez PJ, Storm C, Dee A, Lopez-Sendon JL (2018) A multicentre randomized pilot trial on the effectiveness of different levels of cooling in comatose survivors of out-of-hospital cardiac arrest: the FROST-I trial. Intensive Care Med 44:1807-1815

5. Lemkes JS, Janssens GN, van der Hoeven NW, Jewbali LSD, Dubois EA, Meuwissen M, Rijpstra TA, Bosker HA, Blans MJ, Bleeker GB, Baak R, Vlachojannis GJ, Eikemans BJW, van der Harst P, van der Horst ICC, Voskuil M, van der Heijden JJ, Beishuizen A, Stoel M, Camaro C, van der Hoeven $H$, Henriques JP, Vlaar APJ, Vink MA, van den Bogaard B, Heestermans T, de Ruijter W, Delnoij TSR, Crijns H, Jessurun GAJ, Oemrawsingh PV, Gosselink MTM, Plomp K, Magro M, Elbers PWG, van de Ven PM, Oudemans-van Straaten HM, van Royen N (2019) Coronary angiography after cardiac arrest without ST-segment elevation. N Engl J Med 380:1397-1407

6. Bougouin W, Dumas F, Karam N, Maupain C, Marijon E, Lamhaut L, Jost D, Geri G, Beganton F, Varenne O, Spaulding C, Jouven X, Cariou A (2018) Should we perform an immediate coronary angiogram in all patients after cardiac arrest?: Insights from a large French registry. JACC CardiovasC Interv 11:249-256

7. Jakkula P, Pettila V, Skrifvars MB, Hastbacka J, Loisa P, Tiainen M, Wilkman E, Toppila J, Koskue T, Bendel S, Birkelund T, Laru-Sompa R, Valkonen M, Reinikainen M, group Cs (2018) Targeting low-normal or high-normal mean arterial pressure after cardiac arrest and resuscitation: a randomised pilot trial. Intensive Care Med 44:2091-2101

8. Jakkula P, Reinikainen M, Hastbacka J, Loisa P, Tiainen M, Pettila V, Toppila J, Lahde M, Backlund M, Okkonen M, Bendel S, Birkelund T, Pulkkinen A,
Heinonen J, Tikka T, Skrifvars MB, group Cs (2018) Targeting two different levels of both arterial carbon dioxide and arterial oxygen after cardiac arrest and resuscitation: a randomised pilot trial. Intensive Care Med 44:2112-2121

9. Sandroni C, Parnia S, Nolan JP (2019) Cerebral oximetry in cardiac arrest: a potential role but with limitations. Intensive Care Med 45:904-906

10. Taccone FS, Crippa IA, Creteur J, Rasulo F (2018) Estimated cerebral perfusion pressure among post-cardiac arrest survivors. Intensive Care Med 44:966-967

11. Moseby-Knappe M, Mattsson N, Nielsen N, Zetterberg H, Blennow K, Dankiewicz J, Dragancea I, Friberg H, Lilja G, Insel PS, Rylander C, Westhall E, Kjaergaard J, Wise MP, Hassager C, Kuiper MA, Stammet P, Wanscher MCJ, Wetterslev J, Erlinge D, Horn J, Pellis T, Cronberg T (2019) Serum neurofilament light chain for prognosis of outcome after cardiac arrest. JAMA Neurol 76:64-71

12. Oddo M, Sandroni C, Citerio G, Miroz JP, Horn J, Rundgren M, Cariou A, Payen JF, Storm C, Stammet P, Taccone FS (2018) Quantitative versus standard pupillary light reflex for early prognostication in comatose cardiac arrest patients: an international prospective multicenter doubleblinded study. Intensive Care Med 44:2102-2111

13. Velly L, Perlbarg V, Boulier T, Adam N, Delphine S, Luyt C-E, Battisti V, Torkomian G, Arbelot C, Chabanne R, Jean B, Di Perri C, Laureys S, Citerio G, Vargiolu A, Rohaut B, Bruder N, Girard N, Silva S, Cottenceau V, Tourdias T, Coulon O, Riou B, Naccache L, Gupta R, Benali H, Galanaud D, Puybasset L, Constantin J-M, Chastre J, Amour J, Vezinet C, Rouby J-J, Raux M, Langeron O, Degos V, Bolgert F, Weiss N, Similowski T, Demoule A, Duguet A, Tollard E, Veber B, Lotterie J-A, Sanchez-Pena P, Génestal M, Patassini M (2018) Use of brain diffusion tensor imaging for the prediction of longterm neurological outcomes in patients after cardiac arrest: a multicentre, international, prospective, observational, cohort study. Lancet Neurol 17:317-326 